TITLE:

\title{
Phosphatidylserine exposure in living cells
}

$\operatorname{AUTHOR}(\mathrm{S})$ :

Shin, Hye Won; Takatsu, Hiroyuki

\section{CITATION:}

Shin, Hye Won ... [et al]. Phosphatidylserine exposure in living cells.

Critical Reviews in Biochemistry and Molecular Biology 2020, 55(2): 166178

\section{ISSUE DATE:}

2020

URL:

http://hdl.handle.net/2433/252464

\section{RIGHT:}

This is an Accepted Manuscript of an article published by Taylor \& Francis in 'Critical Reviews in Biochemistry and Molecular Biology' on 2020, available online: https://www.tandfonline.com/10.1080/10409238.2020.1758624; The fulltext file will be made open to the public on 14 May 2021 in accordance with publisher's 'Terms and Conditions for SelfArchiving.'; この論文は出版社版でありません。引用の際には出版社版をご確認ご利用ください。; This is not the published version. Please cite only the published version. 


\section{Phosphatidylserine exposure in living cells}

Hye-Won Shin* and Hiroyuki Takatsu

Graduate School of Pharmaceutical Sciences, Kyoto University, Sakyo-ku, Kyoto 6068501, Japan

* Correspondence should be addressed to H.-W.S. (e-mail: shin@pharm.kyoto-u.ac.jp)

\section{Key Words}

Lipid bilayer, phosphatidylserine, P4-ATPase, flippase, scramblase 


\begin{abstract}
P4-ATPases, a subfamily of P-type ATPases, translocate cell membrane phospholipids from the exoplasmic/luminal leaflet to the cytoplasmic leaflet to generate and maintain membrane lipid asymmetry. Exposure of phosphatidylserine (PS) in the exoplasmic leaflet is well known to transduce critical signals for apoptotic cell clearance and platelet coagulation. PS exposure is also involved in many other biological processes, including myoblast and osteoclast fusion, and the immune response. Moreover, mounting evidence suggest that PS exposure is critical for neuronal regeneration and degeneration. In apoptotic cells, PS exposure is induced by irreversible activation of scramblases and inactivation of P4-ATPases. However, how PS is reversibly exposed and restored in viable cells during other biological processes remains poorly understood. In the present review, we discuss the physiological significance of reversible PS exposure in living cells, and the putative roles of flippases, floppases, and scramblases.
\end{abstract}




\section{Introduction}

Cell membrane lipid bilayers exhibit asymmetric lipid distribution. In mammalian cells, the aminophospholipids phosphatidylserine (PS) and phosphatidylethanolamine (PE) are restricted to the cytoplasmic leaflet, while phosphatidylcholine (PC), sphingomyelin, and glycosphingolipids are enriched in the exoplasmic leaflet (Devaux, 1991; Falzone et al., 2018; Murate et al., 2015; Nagata et al., 2016; Zachowski, 1993). This transbilayer lipid asymmetry is generated and regulated by lipid flippases, floppases, and scramblases.

In normal physiological conditions, PS is generally absent from the exoplasmic leaflet of the plasma membrane. Exposure of PS at the cell surface is atypical and activates important biological processes that can determine the cell's fate. PS exposure has been classically observed in cells fated for disposal, such as apoptotic cells and platelets during blood aggregation. However, PS exposure also occurs in non-apoptotic cells. The physiological significance and molecular mechanisms of PS exposure in living cells are elusive and represent an emerging subject in the field of biology. In the present review, we discuss several contexts in which PS is exposed by living cells, their physiological significance, and potential reversible mechanisms by which PS can be transiently exposed. 


\section{Flippases, floppases, and scramblases}

PS is removed from the extracellular surface by ATP-dependent active transport, which is regulated by members of the P4-ATPase family (Figure 1). The P4-ATPase family is a subfamily of the P-type ATPase superfamily. All P-type ATPases form an acidstable aspartyl phosphate intermediate during the reaction cycle and are so named "Ptype." Although P-type ATPases primarily facilitate the transport of cations across biological membranes, the P4-ATPase subfamily vectorially translocates lipids from the exoplasmic/luminal to the cytosolic leaflet.

Mammalian P4-ATPases exhibit strict substrate specificities (Table 1), and PSspecific P4-ATPases are responsible for the removal of cell surface PS (Figure 1). Among the P4-ATPases summarized in Table 1, ATP11A and ATP11C are major plasma membrane PS flippases in many cell types (Liou et al., 2019; Segawa et al., 2014; Siggs et al., 2011a; Takada et al., 2015; Tsuchiya et al., 2018; Wang et al., 2018; Yabas et al., 2011) and ATP8A1 and ATP8A2 also flip PS (Coleman et al., 2009; Paterson et al., 2006). ATP8B1, ATP8B2, and ATP10A preferentially flip PC at the plasma membrane (Naito et al., 2015; Takada et al., 2015; Takatsu et al., 2014), and ATP10D translocates a glycosphingolipid, glucosylceramide, but not any other phospholipids (Roland et al., 2019). Recently, ATP10B appeared to translocate PC and glucosylceramide (Martin et al., 2020). Most P4-ATPases, with the exception of ATP9A and ATP9B, interact with $\mathrm{CDC} 50 \mathrm{~A}$ or $\mathrm{B}$, a chaperone-like protein that is required for their transport from the endoplasmic reticulum (ER) to the plasma membrane and/or intracellular compartments (Figure 1 and Table 1) (Shin and Takatsu, 2019; Takatsu et al., 2011).

Cryo-EM structures of ATP8A1 and Drs2p (a saccharomyces cerevisiae P4-ATPase) with CDC50 protein have published (Bai et al., 2019; Hiraizumi et al., 2019; Timcenko et al., 2019) and the crystal structure of ATP11C with CDC50A is disclosed (doi: 10.1101/2019.12.23.881698). In all structures, the substrate PS is thought to transport along the transmembrane (TM) 4 and the transporting crevice is mainly composed of TM2, 4, and 6. The C-terminal regions of ATP8A1 and Drs2p play regulatory roles for transporting of PS (Bai et al., 2019; Hiraizumi et al., 2019; Timcenko et al., 2019). The putative PS entry site of ATP8A1 would be between TM1-TM2 and TM3-TM4 (Hiraizumi et al., 2019) and that of ATP11C would be a cavity between CDC50A exoplasmic domain and the ATP11C TM3-TM4 loop (doi: 10.1101/2019.12.23.881698).

In mice, ATP11C mutations are associated with abnormal B-cell development and anemia secondary to abnormal erythrocyte shape (Siggs et al., 2011a; Yabas et al., 2014; Yabas et al., 2011). ATP $11 C$ is located on the $\mathrm{X}$ chromosome, and a missense mutation in this locus occurs in a male patient with congenital hemolytic anemia (Arashiki et al., 
2016), suggesting that ATP11C activity is important for hematopoietic cell homeostasis. In addition, both ATP11A and ATP11C are implicated in PS exposure on apoptotic cells, and are cleaved by caspases (Segawa et al., 2016). ATP8A1, another PS-flippase, plays a key role in hippocampal cells, as PS externalization is increased in the hippocampal cells of mice lacking Atp8al, which exhibit deficient hippocampus-dependent learning (Levano et al., 2012). ATP8A2 is a causative gene for cerebellar ataxia, mental retardation and disequilibrium syndrome (CAMRQ) (Onat et al., 2013) and other ATP8A2 mutations are related to intellectual disability and severe neurological phenotypes (Cacciagli et al., 2010; Martin-Hernandez et al., 2016), suggesting that ATP8A2 is critical for the development of the nervous system. Atp $8 a 2$ deficient mice exhibit the degeneration of photoreceptor cells (Coleman et al., 2014; Zhu et al., 2012).

CDC50A (Tmem30a) is essential for early embryonic development in mice and neuronal knockout of Tmem30a also led to embryonic lethality (Yang et al., 2018), Because CDC50A is required for folding and transporting of multiple P4-ATPases to their cellular destinations (Table 1), CDC50A knockout disrupts P4-ATPases which may function in broad range of tissues at various developmental stages. Accordingly, several conditional Tmem30a knockout mice have been produced. Purkinje cell-specific Tmem30a knockout mice show the degeneration of the Purkinje cells in cerebellum via apoptotic cell death (Yang et al., 2018). Moreover, conditional Tmem30a knockout mice led to loss of cone cells (Zhang et al., 2017), degeneration of rod bipolar cells probably via apoptosis (Yang et al., 2019), and retarded retinal vascular development (Zhang et al., 2019). These phenotypes of the specific Tmem $30 a$ knockout might be due to the functional loss of P4-ATPases, probably ATP8A1 and/or ATP8A2 since the P4-ATPases are involved in the development of nerve cells and retinal function (Coleman et al., 2014; Levano et al., 2012; Zhu et al., 2012). Moreover, liver-specific Tmem30a knockout causes hepatic disorder (Liu et al., 2017). The phenotype might be related to the defect in ATP8B1 or ATP11C because mutations in ATP8B1 and defect in Atp1 1c cause hepatic cholestasis (Bull et al., 1998; Siggs et al., 2011b). In addition, conditional Tmem30a knockout mice resulted in depletion of hematopoietic cell lineage (Li et al., 2018). Since all phenotypes observed in the Tmem30a knockout mice are most likely due to the functional loss of multiple P4-ATPases, the pathophysiological mechanisms remain unknown.

Some ATP-binding cassette $(\mathrm{ABC})$ transporters facilitate membrane lipid transport in the opposite direction, from the cytosolic to the exoplasmic/luminal leaflet, in an ATPdependent manner (Figure 1 and Table 2). However, it is presently unclear whether this transport is associated with flopping, efflux, or both. Many ABC transporters do not 
exhibit strict substrate specificities (Table 2) (Coleman et al., 2013; Neumann et al., 2017 ; van Meer et al., 2008), but a specific member of this family could be responsible for signal-dependent PS exposure (Hisamoto et al., 2018). Mutations in PC-flopping ABCB4 and PC-flipping ATP8B1 cause progressive familial intrahepatic cholestasis (Bull et al., 1998; Jacquemin et al., 2001; Smit et al., 1993; Takatsu et al., 2014) indicating that the flip-flop of PC in bile canaliculi is important for homeostasis of bile secretion.

The rapid collapse of lipid asymmetry of the plasma membrane, which results in PS exposure, is accomplished by phospholipid scrambling. Lipid scramblases translocate lipids rapidly and bidirectionally down their concentration gradients, but are generally not selective for lipids (Figure 1) (Bevers and Williamson, 2016; Sahu et al., 2007). Scramblases facilitate PS exposure in activated platelets and apoptotic cells (Suzuki et al., 2013a; Suzuki et al., 2010). Two major families of regulated scramblases have thus far been identified, the TMEM16 family and the Xk-related (Xkr) family (Table 3).

There are 10 human TMEM16 proteins, including TMEM16A-H and TMEM16 J-K (Figure 1). TMEM16A and B were initially identified as $\mathrm{Ca}^{2+}$-activated chloride channels (Table 3) (Caputo et al., 2008; Schroeder et al., 2008; Yang et al., 2008). Mammalian TMEM16C, D, E, F, G, J, and K are primarily associated with scramblase activity (Gyobu et al., 2016; Suzuki et al., 2013b; Tsuji et al., 2019). A recent study suggests that TMEM16J could be a cation channel (Kim et al., 2018). TMEM16F and fungal nhTMEM16 and afTMEM16 contain dual-function channels/scramblases (Brunner et al., 2014; Malvezzi et al., 2013; Scudieri et al., 2015).

Members of the Xkr family of membrane proteins are caspase-activated scramblases involved in PS exposure during apoptosis (Nagata et al., 2016; Suzuki et al., 2014). The $\mathrm{Xkr}$ family is comprised of nine human members (Table 3), each of which contains 6-10 predicted transmembrane domains. Xkr8 protein was recently identified as being activated by either caspase cleavage or phosphorylation (Sakuragi et al., 2019). Moreover, some G protein-coupled receptors (GPCRs) are potential nonregulated scramblases (Goren et al., 2014; Menon et al., 2011).

\section{PS Exposure in cellular processes}

PS exposure in apoptotic cells

PS is exposed on the surface of apoptotic cells and serves as an 'eat me' signal for clearance of the cells by macrophages (Fadok et al., 1992; Nagata, 2018). Suzuki et al. demonstrated that members of the Xkr family mediate $\mathrm{Ca}^{2+}$-independent PS exposure during apoptosis (Suzuki et al., 2014; Suzuki et al., 2016). Deletion of the $X k r 8$ gene in cultured cells abolishes PS exposure in response to apoptotic stimuli, and transient 
expression of Xkr4, Xkr8, or Xkr9 rescues this response (Suzuki et al., 2014; Suzuki et al., 2016). These proteins contain a caspase recognition site at the C-terminal domain, which is cleaved by caspases 3 and 7 for activation (Figure 2) (Suzuki et al., 2013a; Suzuki et al., 2014). The C. elegans Xkr ortholog CED-8 is involved in caspasedependent PS externalization in apoptotic cells (Chen et al., 2013; Li et al., 2015), suggesting an evolutionarily conserved scramblase function for these proteins.

At the same time, caspases 3 and 7 cleave and inactivate ATP11A and ATP11C, major PS flippases that regulate transport of PS to the cytosolic leaflet at the plasma membrane (Figure 2) (Segawa et al., 2016; Segawa et al., 2014). Cells expressing caspase-resistant ATP11C do not expose PS during apoptosis and are not phagocytosed by macrophages, suggesting that inactivation of PS flippases is required for PS exposure in apoptotic cells (Segawa et al., 2014). Thus, caspase-dependent activation of Xkr8 and inactivation of P4ATPases leads to sustained PS exposure in apoptotic cells (Figure 2).

PS is also exposed during non-apoptotic cell death such as necroptosis, which is important in host immune defense against pathogens, although the key players have not yet been elucidated. Although the non-apoptotic cell death would not be discussed in this review, recent review can be refereed has been published about non-apoptotic cell death (Shlomovitz et al., 2019).

\section{PS exposure in platelets}

PS is critical for blood coagulation and is exposed on the cell surface of activated platelets in a $\mathrm{Ca}^{2+}$-dependent manner. PS exposure creates scaffolds that allow aggregation of various coagulation factors (Bevers et al., 1983) (Bevers and Williamson, 2016). Scott syndrome, a mild autosomal bleeding disorder, is caused by deficient $\mathrm{Ca}^{2+}$ dependent PS exposure in activated platelets (Wielders et al., 2009). Patients carrying Scott syndrome exhibited a homozygous null mutation or complex heterozygous mutations of the TMEM16F gene (Castoldi et al., 2011; Suzuki et al., 2013a). Moreover, dogs carrying Canine Scott syndrome, a naturally occurring bleeding disorder, lack procoagulant activity in activated platelets and carry a point mutation in the TMEM16F gene causing an absence of platelet TMEM16F (Brooks et al., 2015). The phenotypes of platelet-specific TMEM16F-null mice resemble those of patients with Scott syndrome (Fujii et al., 2015). These findings suggest that the TMEM16F scramblase is responsible for PS exposure in activated platelets.

Platelet activation leads to dramatic changes in platelet morphology. Microparticles are generated from platelet plasma membrane shedding during platelet activation (DacharyPrigent et al., 1995). Microparticles express platelet membrane receptors, expose PS on 
their surfaces, and play an important role in hemostasis and thrombosis (Bevers et al., 1991). Microparticle release is severely reduced in the absence of TMEM16F (Fujii et al., 2015), and platelets from Scott syndrome patients exhibit defective microparticle release (Sims et al., 1989), suggesting that PS exposure and/or scrambling activity is involved in membrane shape changes and microparticle formation. Because greater PC flipping activity at the plasma membrane can drive inward membrane curvature (Takada et al., 2018), lipid translocating activity could affect these membrane shape changes.

\section{PS exposure in living cells}

PS exposure in apoptotic cells and in activated platelets occurs irreversibly. However, it also occurs reversibly in living cells. Here, we discuss several contexts in which PS is exposed by living cells, their physiological significance, and potential reversible mechanisms by which PS can be transiently exposed and recovered.

Viral infection The presence of PS in the target membrane promotes fusion of many enveloped viruses (Coil and Miller, 2005). Human immunodeficiency virus 1 (HIV-1) entry into host cells is initiated by interaction of the viral envelope glycoprotein (Env), and cellular CD4 receptors and coreceptors. $\mathrm{Ca}^{2+}$ signaling is triggered by engagement of the coreceptors with Env (Melar et al., 2007; Wilen et al., 2012). HIV-1-induced PS redistribution depends on $\mathrm{Ca}^{2+}$ signaling and involves the lipid scramblase TMEM16F (Zaitseva et al., 2017). Externalized PS strongly promotes Env-mediated membrane fusion and HIV-1 infection. Blocking PS externalization with PS binding proteins or suppression of TMEM16F function inhibits Env-mediated fusion (Zaitseva et al., 2017). Therefore, cell surface PS acts as an important cofactor that promotes fusogenic complex formation (Zaitseva et al., 2017). Similar to HIV-1, binding of the alpha-herpesvirus envelope glycoprotein to the viral receptor induces $\mathrm{Ca}^{2+}$ signaling and PS exposure on the plasma membrane, facilitating fusion (Azab et al., 2015). Moreover, vesicular stomatitis virus (VSV)-mediated fusion also requires an interaction between a VSV glycoprotein and PS at the plasma membrane (Carneiro et al., 2002). Other anionic lipids also appear to be required for VSV particle fusion (Matos et al., 2013).

Myoblast fusion Transient exposure of PS occurs in mouse embryonic myotubes on embryonic day 13 (E13), a stage of development when primary myotubes are formed. Mammalian skeletal muscles are formed by fusion of mononucleated precursor cells (myoblasts) into unusually elongated multinucleated cells known as myotubes, whose formation relies on complexed cell-to-cell fusion and elongation of multinucleated 
syncytia (Abmayr and Pavlath, 2012). During myotube formation, PS transiently translocates to the outer leaflet of the plasma membrane, and recognition of PS on the cell surface by PS receptors induces contact-dependent signaling to promote fusion with neighboring myoblasts (Hochreiter-Hufford et al., 2013; Leikina et al., 2013; Park et al., 2016; van den Eijnde et al., 2001).

Annexins A1 and A5, which interact with many cell surface proteins (Moss and Morgan, 2004) and PS, facilitate myotube formation by direct or indirect regulation of membrane fusion (Leikina et al., 2013). The PS receptor BAI-1 recognizes PS-exposing apoptotic cells, and a subsequent signaling cascade induces myoblast fusion (Hochreiter-Hufford et al., 2013). Another PS receptor, stabilin-2, contributes to myoblast fusion during muscle growth and regeneration in a PS-dependent manner (Park et al., 2016). Because caspase inhibitors fail to block myotube formation, PS exposure (van den Eijnde et al., 2001), and stabilin-2-mediated myoblast fusion (Park et al., 2016), apoptosis might not be essential for myotube formation although the requirement of apoptotic cells was previously reported (Hochreiter-Hufford et al., 2013). Recently, Tsuchiya et al. demonstrated that recovery of exposed PS is critical for the regulation of the $\mathrm{Ca}^{2+}$ channel PIEZO1, which is indispensable for proper morphogenesis during myotube formation. The phospholipid flippase ATP11A is responsible for the recovery of exposed PS (Tsuchiya et al., 2018), which could be a prerequisite for PIEZO1 activation.

TMEM16E is mutated in humans with myopathies associated with abnormal muscle regeneration (Bolduc et al., 2010; Whitlock and Hartzell, 2017). Mice lacking TMEM16E are defective in myoblast fusion necessary for the proper repair and regeneration of myotubes (Griffin et al., 2016) suggesting that scramblase activity is required for the fusion of myoblasts to regenerate myotubes. Moreover, the mice exhibit the compromised recovery of muscle fibers following laser damage, which can induce membrane pores. Similarly, TMEM16F is critical for PS exposure and the plasma membrane repair of the damaged membranes by treatment with a pore-forming reagent (Wu et al., 2020). Therefore, the scrambling activity and PS exposure would be critical for the membrane repair process.

Osteoclast fusion Similar to myotube formation by myoblast fusion, PS is exposed during the formation of inflammatory giant cells from macrophage fusion (Helming and Gordon, 2009) and placental syncytiotrophoblast formation from trophoblast fusion (Lyden et al., 1993). Cell surface PS influences differentiation processes in osteoclasts (Wu et al., 2010), and myoblasts require PS exposure for pre-fusion steps. Bone-resorbing multinucleated osteoclasts, which play central roles in bone maintenance and repair, arise 
from the fusion of mononuclear osteoclast precursors from the monocyte or macrophage lineage. Cell-cell fusion is not essential for bone resorption, but bone-resorbing ability is greatly decreased in mononuclear osteoclasts (Helming and Gordon, 2009; Yagi et al., 2005). Osteoclast deficiencies or dysfunction lead to osteopetrosis, a rare congenital disease characterized by high bone density and impaired bone marrow cavity formation. Contrastingly, increased osteoclast activity leads to osteoporosis and mediates joint destruction in rheumatoid arthritis (Helming and Gordon, 2009). Osteoclast fusion requires dendrocyte-expressed seven transmembrane protein (DC-STAMP)-dependent non-apoptotic PS exposure at the surface of fusion-committed cells (Verma et al., 2018; Yagi et al., 2005). This fusion is also dependent on extracellular annexins and PS binding proteins, which, together with the annexin-binding protein S100A4, regulate the fusogenic activity of syncytin 1 (Verma et al., 2018). Thus, the cell fusion step of osteoclastogenesis is controlled by the PS-mediated activity of several proteins.

Neuronal degeneration/regeneration Recent evidence has linked PS exposure to neurite degeneration (Sapar et al., 2018; Wakatsuki and Araki, 2017). Phagocytic clearance of degenerating dendrites or axons is critical for maintaining tissue homeostasis and preventing neuroinflammation (Nagata, 2010; Salter and Stevens, 2017). Exposed PS is postulated to be an 'eat-me' signal, allowing phagocyte recognition of degenerating neurites. Either the scramblase $\mathrm{Xkr} 8$ or the lipid translocase $\mathrm{ABC} 1$ (a member of the ABC transporter family) is involved in PS exposure during axon degeneration in cultured murine dorsal root ganglion neurons (Wakatsuki and Araki, 2017). In D. melanogaster, PS is also exposed on degenerating dendrites during developmental pruning and after physical injury. PS exposure can also be induced by either knockout of the phospholipid flippase ATP8A or overexpression of the scramblase TMEM16, which causes phagocytes to break down PS-exposing neurites (Sapar et al., 2018). Moreover, knockout of CDC50 and overexpression of scramblase can lead to dendrite reduction. Mammalian orthologs of ATP8A, including ATP8A1 and 2, flip PS (Table 1) (Coleman et al., 2009; Lee et al., 2015), suggesting ATP8A could be responsible for PS asymmetry in drosophila dendrites. Therefore, both the inhibition of flippases and the activation of scramblases appear to be associated with PS exposure and neurite degeneration.

Following axon injury, a cascade of signaling events initiates axon regeneration. Neumann et al. demonstrated that axon injury in the nervous system of C. elegans results in PS exposure, which functions as a signal to promote axon reconnection and fusion, consequently re-establishing axonal integrity (Neumann et al., 2015). Axon injury induces PS accumulation around injured axons, which is dependent on the caspase- 
activated ABC transporter CED-7 in C. elegans (Hisamoto et al., 2018). PS also functions as a critical signal for triggering the initiation of axon regeneration through the apoptotic clearance molecules CED-7 and CED-3 after injury. PS-associated thyretin (TTR)-11 may then activate integrin, thereby initiating axon regeneration (Hisamoto et al., 2018). Thus, components of the apoptotic cascade can also play protective roles in axonal regeneration.

Fertilization The plasma membrane of spermatozoa, like that of other mammalian cells, exhibit transbilayer phospholipid asymmetry (Gadella et al., 1999). Upon capacitation, in which sperm cells are prepared for binding and penetration of the zona pellucida, phospholipid scrambling appears to occur (Gadella and Harrison, 2000). A recent study identified that PS is exposed on the head region of viable and motile sperm, and that masking sperm PS inhibits fertilization (Rival et al., 2019). On oocytes, the PS receptors BAI1/3, CD36, Tim-4, and Mer-TK contribute to fertilization. Therefore, PS exposure in viable sperm and PS receptors on oocytes are critical for sperm-egg fusion.

The mouse ortholog of ATP8B3, a putative sperm aminophospholipid transporter (SAPLT), is expressed in the acrosomal region of the spermatozoal head and has been implicated in capacitation (Wang et al., 2004). In SAPLT-null spermatozoa, PS is exposed on the outer leaflet prior to sperm capacitation, suggesting that SAPLT is required for PS asymmetry. Fertilization rates are normal when the null spermatozoa are added to zona pellucida-free eggs, but in the presence of the extracellular matrix, fewer null spermatozoa bind or penetrate the zona pellucida, and fewer undergo acrosome reactions, indicating that regulated PS externalization is critical for sperm capacitation.

The murine P4-ATPase ATP8B5, originally identified as flippase expressed in testis splicing form A (FetA), is absent in humans. ATP8B5 is expressed in gamete cells, and its localization is tightly associated with acrosome biogenesis, a process that involves intensive intracellular vesicle formation and fusion. ATP8B5 depletion perturbs Golgi organization and secretion, suggesting that ATP8B5 plays a role in spermatogenesis (Xu et al., 2009). It is currently unknown whether CDC50 is a partner of ATP8B3 and ATP8B5. CDC50C is specifically expressed in mouse testis, and thus is presumed to be an ATP8B3 and/or ATP8B5 partner. However, CDC50C is not present in the human gene database, and human ATP8B3 remained in the ER when coexpressed with either CDC50A or CDC50B in HeLa cells (Shin and Takatsu, 2019) (our unpublished data). This suggested that the two CDC50s might not be partners of ATP8B3, or that ATP8B3 could be an ERlocalizing human P4-ATPase.

TMEM16E is expressed in germ cells during early spermatogenesis and is localized to 
the sperm tail. TMEM16E localizes to the ER and appears to function as a lipid scramblase (Gyobu et al., 2016). TMEM16E-null sperm exhibit no apparent defects in morphology, capacitation, PS exposure during capacitation, or binding to the zona pellucida. However, the null sperm exhibit low motility, particularly after capacitation, although the mechanism of TMEM16E function remains unknown.

Immune response Activated immune cells were observed to expose PS nearly two decades ago, but the physiological relevance of PS exposure has still been obscure. We here summarize several examples of PS exposure in immune cells in order to provide insight into the relationship between PS exposure and immune response. Neutrophils stimulated with the chemotactic peptide formylated Met-Leu-Phe (fMLP) transiently expose PS on the cell surface (Frasch et al., 2004). Moreover, PS exposure is accompanied by enhanced uptake of several lipid probes, including NBD-PS and NBD-PC during fMLP stimulation, suggesting that lipid scrambling might be activated. PS exposure is not associated with apoptosis in activated neutrophils (Frasch et al., 2004). Moreover, several members of the human galectin family of glycan binding proteins, galectins-1, -2, and 4 , induce PS exposure in activated but not resting human neutrophils and in several leukocyte cell lines (Stowell et al., 2007). Although PS exposure is evidently important for the immune response in activated leukocytes, its mechanism and physiological relevance in this context remain unclear.

PS is exposed at high levels on a subpopulation of T-lymphocytes, where it is required for activation of the $\mathrm{P} 2 \mathrm{X} 7$ cation channel. Changes in the intracellular ion homeostasis by P2X receptor stimulation trigger inflammation (Di Virgilio et al., 2018). High PS levels in the inner leaflet of the plasma membrane appear to inhibit P2X7 and prevent channel opening (Elliott et al., 2005). On the other hand, in myoblasts, high levels of PS in the outer leaflet of the plasma membrane inhibit activation of the PIEZO1 ion channel, perturbing normal myotube formation (Tsuchiya et al., 2018). Therefore, PS distribution in the lipid bilayer is important for the regulation of membrane transporters, including ion channels.

IgE receptor stimulation rapidly induces reversible PS exposure in viable mast cells (Martin et al., 2000). Ionomycin, $\mathrm{Ca}^{2+}$ ionophore, treatment induces both PS exposure and degranulation in mast cells, suggesting that PS exposure depends on factors downstream of $\mathrm{Ca}^{2+}$, and could thus be related to the exocytic event. However, how PS exposure is associated with the degranulation process remains unknown.

In addition, cell surface PS appears at the exocytic sites in activated chromaffin cells (Ory et al., 2013). PS exposure is required for compensatory endocytosis, but is not 
required for exocytosis or constitutive endocytosis. Compensatory endocytosis is triggered subsequently to the supply of secretory granule membranes after calciumregulated exocytosis. Because calcium-regulated exocytosis and compensatory endocytosis are tightly coupled, PS reorganization is critical in the endocytic phase of regulated neuroendocrine secretion (Ory et al., 2013). However, the mechanisms of PS reorganization during exocytosis and compensatory endocytosis remain elusive.

\section{Perspectives: How is transient PS exposure regulated?}

As described above, transient PS exposure occurs in many cell types and biological processes. However, the physiological relevance and molecular mechanisms of transient PS exposure remain unclear. Apoptotic PS exposure requires not only the activation of scramblases, but also the inhibition of P4-ATPase flippases (Segawa et al., 2014). Moreover, increased cytosolic $\mathrm{Ca}^{2+}$ in human erythrocytes inhibits incorporation of aminophospholipids (Bitbol et al., 1987), and $\mathrm{Ca}^{2+}$-dependent protein kinase C (PKC) $\alpha$ activation mediates scramblase activation, flippase inhibition, and subsequent PS exposure (Noh et al., 2010; Wesseling et al., 2016). Therefore, transient PS exposure could be potentiated by inhibition of PS flippases upon $\mathrm{Ca}^{2+}$-dependent signaling, as well as by activation of scramblases. Indeed, the ATPase activities of ATP8A1, ATP8A2, ATP11A, and ATP11C are inhibited by high calcium concentrations (Segawa et al., 2016) (Chalat et al., 2017). The C-terminal region of ATP8A2 appear to play a complexed regulatory role for its ATPase activity via phosphorylation of the $\mathrm{C}$-terminal region by CaMKII (calcium/calmodulin-dependent protein kinase II) (Chalat et al., 2017). The interaction between an autoinhibitory and an anti-autoinhibitory domain in the C-terminal region of ATP8A2 would be dissociated by the phosphorylation resulting in an inhibition of ATP8A2 activity (Chalat et al., 2017). Importantly, ATP11C is endocytosed by $\mathrm{Ca}^{2+}$ signaling-dependent phosphorylation of its C-terminal cytoplasmic tail (Figure 3) (Takatsu et al., 2017). ATP11C is endocytosed and sequestered from the plasma membrane in response to signal transduction of the Gq-coupled GPCR, which increases cytosolic $\mathrm{Ca}^{2+}$. Notably, ATP11C can be recycled back to the plasma membrane after switching off the signal, allowing PS flipping and recovery of asymmetry (Figure 3) (Takatsu et al., 2017). Therefore, this $\mathrm{Ca}^{2+}$-dependent downregulation and recycling mechanism of ATP11C is likely responsible for signal-dependent PS exposure and recovery, in the various cell types and biological processes described above.

Future directions include the regulatory mechanisms of flippases and floppases/scramblases in PS exposure, and the contribution of PS translocation to diverse biological processes, including those discussed in the present review. 


\section{Disclosure statement}

There are no conflicts of interest to declare.

\section{Funding}

The work was supported by JSPS KAKENHI Grant Numbers JP17H03655 (to H.-W.S.) and JP17K08270 (to H.T.); the Takeda Science Foundation (to H.-W.S.); and the Naito Foundation (to H.-W.S.). 


\section{Figure legends}

Figure 1 Lipid translocases (flippase, floppase, and scramblase).

Cryo-EM structures of P4-ATPase (human ATP8A1, PDB: 6k7m) with CDC50A (gray) (Hiraizumi et al., 2019), ABC transporter (human ABCB1, PDB: 6c0v) (Kim and Chen, 2018), and scramblase (mouse TMEM16F dimer, PDB: 6p46) (Feng et al., 2019). The enzymatic activity of P4-ATPase allows the aminophospholipids PS and PE to translocate to the cytosolic leaflet of the plasma membrane.

Figure 2 Mechanism of PS exposure in apoptotic cells.

Following the apoptotic cascade, activated caspases cleave between the $\mathrm{N}$ - and P-domains of the PS flippases ATP11A and ATP11C and inactivate them, and cleave and activate the scramblase Xkr8. As a result of flippase inactivation and scramblase activation, PS is persistently exposed on the apoptotic cell surface, allowing phagocytosis by macrophages. A, actuator domain; P, phosphorylation domain; N, nucleotide binding domain.

Figure 3 Model for transient PS exposure and recovery by regulation of ATP11C.

(1) Cytosolic $\mathrm{Ca}^{2+}$ influx is induced by Gq-coupled receptor-mediated signal transduction.

(2) Phospholipase C hydrolyzes phosphatidyl 4,5-bisphosphate to inositol 1,4,5trisphosphate (IP3) and diacylglycerol (DAG). (3) (4) IP3 stimulates increased cytosolic $\mathrm{Ca}^{2+}$ concentration. (5) $\mathrm{PKC} \alpha$ is activated by binding with $\mathrm{Ca}^{2+}$ and DAG. (6) PKC $\alpha$ phosphorylates the C-terminus of ATP11C, resulting in generation of a di-leucine motif, which recruits the AP-2 clathrin adaptor protein complex. (7) ATP11C is sequestered from the plasma membrane via clathrin-mediated endocytosis, (8) decreasing plasma membrane PS flipping activity. (9) (10) Increased cytosolic $\mathrm{Ca}^{2+}$ could activate $\mathrm{Ca}^{2+}$ dependent scramblases (such as TMEM16 members), resulting in local PS exposure. (11) ATP11C is recycled back to the plasma membrane after the signaling is switched off. (12) Exposed PS is recovered to the cytosolic leaflet. 


\section{References}

Abmayr, S.M., and G.K. Pavlath. 2012. Myoblast fusion: lessons from flies and mice. Development. 139:641-656.

Andersen, J.P., A.L. Vestergaard, S.A. Mikkelsen, L.S. Mogensen, M. Chalat, and R.S. Molday. 2016. P4-ATPases as Phospholipid Flippases-Structure, Function, and Enigmas. Front Physiol. 7:275.

Arashiki, N., Y. Takakuwa, N. Mohandas, J. Hale, K. Yoshida, H. Ogura, T. Utsugisawa, S. Ohga, S. Miyano, S. Ogawa, S. Kojima, and H. Kanno. 2016. ATP11C is a major flippase in human erythrocytes and its defect causes congenital hemolytic anemia. Haematologica. 101:559-565.

Azab, W., A. Gramatica, A. Herrmann, and N. Osterrieder. 2015. Binding of alphaherpesvirus glycoprotein $\mathrm{H}$ to surface alpha4beta1-integrins activates calcium-signaling pathways and induces phosphatidylserine exposure on the plasma membrane. mBio. 6:e01552-01515.

Bai, L., A. Kovach, Q. You, H.C. Hsu, G. Zhao, and H. Li. 2019. Autoinhibition and activation mechanisms of the eukaryotic lipid flippase Drs2p-Cdc50p. Nature communications. 10:4142.

Bevers, E.M., P. Comfurius, and R.F. Zwaal. 1983. Changes in membrane phospholipid distribution during platelet activation. Biochim Biophys Acta. 736:57-66.

Bevers, E.M., P. Comfurius, and R.F. Zwaal. 1991. Platelet procoagulant activity: physiological significance and mechanisms of exposure. Blood Rev. 5:146-154.

Bevers, E.M., and P.L. Williamson. 2016. Getting to the Outer Leaflet: Physiology of Phosphatidylserine Exposure at the Plasma Membrane. Physiological reviews. 96:605-645.

Bitbol, M., P. Fellmann, A. Zachowski, and P.F. Devaux. 1987. Ion regulation of phosphatidylserine and phosphatidylethanolamine outside-inside translocation in human erythrocytes. Biochim Biophys Acta. 904:268-282.

Bolduc, V., G. Marlow, K.M. Boycott, K. Saleki, H. Inoue, J. Kroon, M. Itakura, Y. Robitaille, L. Parent, F. Baas, K. Mizuta, N. Kamata, I. Richard, W.H. Linssen, I. Mahjneh, M. de Visser, R. Bashir, and B. Brais. 2010. Recessive mutations in the putative calcium-activated chloride channel Anoctamin 5 cause proximal LGMD2L and distal MMD3 muscular dystrophies. Am J Hum Genet. 86:213-221.

Brooks, M.B., J.L. Catalfamo, R. MacNguyen, D. Tim, S. Fancher, and J.A. McCardle. 2015. A TMEM16F point mutation causes an absence of canine platelet TMEM16F and ineffective activation and death-induced phospholipid scrambling. Journal of thrombosis and haemostasis : JTH. 13:2240-2252. 
Brunner, J.D., N.K. Lim, S. Schenck, A. Duerst, and R. Dutzler. 2014. X-ray structure of a calcium-activated TMEM16 lipid scramblase. Nature.

Bryde, S., H. Hennrich, P.M. Verhulst, P.F. Devaux, G. Lenoir, and J.C. Holthuis. 2010. CDC50 Proteins Are Critical Components of the Human Class-1 P4-ATPase Transport Machinery. J Biol Chem. 285:40562-40572.

Bull, L.N., M.J. van Eijk, L. Pawlikowska, J.A. DeYoung, J.A. Juijn, M. Liao, L.W. Klomp, N. Lomri, R. Berger, B.F. Scharschmidt, A.S. Knisely, R.H. Houwen, and N.B. Freimer. 1998. A gene encoding a P-type ATPase mutated in two forms of hereditary cholestasis. Nat Genet. 18:219-224.

Cacciagli, P., M.R. Haddad, C. Mignon-Ravix, B. El-Waly, A. Moncla, C. Missirian, B. Chabrol, and L. Villard. 2010. Disruption of the ATP8A2 gene in a patient with a $\mathrm{t}(10 ; 13)$ de novo balanced translocation and a severe neurological phenotype. European journal of human genetics : EJHG. 18:1360-1363.

Calenda, G., J. Peng, C.M. Redman, Q. Sha, X. Wu, and S. Lee. 2006. Identification of two new members, XPLAC and XTES, of the XK family. Gene. 370:6-16.

Caputo, A., E. Caci, L. Ferrera, N. Pedemonte, C. Barsanti, E. Sondo, U. Pfeffer, R. Ravazzolo, O. Zegarra-Moran, and L.J. Galietta. 2008. TMEM16A, a membrane protein associated with calcium-dependent chloride channel activity. Science. 322:590-594.

Carneiro, F.A., M.L. Bianconi, G. Weissmuller, F. Stauffer, and A.T. Da Poian. 2002. Membrane recognition by vesicular stomatitis virus involves enthalpy-driven protein-lipid interactions. J Virol. 76:3756-3764.

Castoldi, E., P.W. Collins, P.L. Williamson, and E.M. Bevers. 2011. Compound heterozygosity for 2 novel TMEM16F mutations in a patient with Scott syndrome. Blood. 117:4399-4400.

Chalat, M., K. Moleschi, and R.S. Molday. 2017. C-terminus of the P4-ATPase ATP8A2 functions in protein folding and regulation of phospholipid flippase activity. Molecular biology of the cell. 28:452-462.

Chen, Y.Z., J. Mapes, E.S. Lee, R.R. Skeen-Gaar, and D. Xue. 2013. Caspase-mediated activation of Caenorhabditis elegans CED-8 promotes apoptosis and phosphatidylserine externalization. Nature communications. 4:2726.

Coil, D.A., and A.D. Miller. 2005. Enhancement of enveloped virus entry by phosphatidylserine. J Virol. 79:11496-11500.

Coleman, J.A., M.C.M. Kwok, and R.S. Molday. 2009. Localization, Purification, and Functional Reconstitution of the P4-ATPase Atp8a2, a Phosphatidylserine Flippase in Photoreceptor Disc Membranes. Journal of Biological Chemistry. 
284:32670-32679.

Coleman, J.A., and R.S. Molday. 2011. Critical Role of the b-Subunit CDC50A in the Stable Expression, Assembly, Subcellular Localization, and Lipid Transport Activity of the P4-ATPase ATP8A2. Journal of Biological Chemistry. 286:1720517216.

Coleman, J.A., F. Quazi, and R.S. Molday. 2013. Mammalian P4-ATPases and ABC transporters and their role in phospholipid transport. Biochimica et Biophysica Acta (BBA) - Molecular and Cell Biology of Lipids. 1831:555-574.

Coleman, J.A., X. Zhu, H.R. Djajadi, L.L. Molday, R.S. Smith, R.T. Libby, S.W. John, and R.S. Molday. 2014. Phospholipid flippase ATP8A2 is required for normal visual and auditory function and photoreceptor and spiral ganglion cell survival. J Cell Sci. 127:1138-1149.

Dachary-Prigent, J., J.M. Pasquet, J.M. Freyssinet, and A.T. Nurden. 1995. Calcium involvement in aminophospholipid exposure and microparticle formation during platelet activation: a study using Ca2+-ATPase inhibitors. Biochemistry. 34:11625-11634.

Devaux, P.F. 1991. Static and dynamic lipid asymmetry in cell membranes. Biochemistry. 30:1163-1173.

Di Virgilio, F., A.C. Sarti, and F. Grassi. 2018. Modulation of innate and adaptive immunity by P2X ion channels. Curr Opin Immunol. 52:51-59.

Elliott, J.I., A. Surprenant, F.M. Marelli-Berg, J.C. Cooper, R.L. Cassady-Cain, C. Wooding, K. Linton, D.R. Alexander, and C.F. Higgins. 2005. Membrane phosphatidylserine distribution as a non-apoptotic signalling mechanism in lymphocytes. Nat Cell Biol. 7:808-816.

Fadok, V.A., D.R. Voelker, P.A. Campbell, J.J. Cohen, D.L. Bratton, and P.M. Henson. 1992. Exposure of phosphatidylserine on the surface of apoptotic lymphocytes triggers specific recognition and removal by macrophages. J Immunol. 148:22072216.

Falzone, M.E., M. Malvezzi, B.C. Lee, and A. Accardi. 2018. Known structures and unknown mechanisms of TMEM16 scramblases and channels. J Gen Physiol. 150:933-947.

Feng, S., S. Dang, T.W. Han, W. Ye, P. Jin, T. Cheng, J. Li, Y.N. Jan, L.Y. Jan, and Y. Cheng. 2019. Cryo-EM Studies of TMEM16F Calcium-Activated Ion Channel Suggest Features Important for Lipid Scrambling. Cell Rep. 28:567-579 e564.

Frasch, S.C., P.M. Henson, K. Nagaosa, M.B. Fessler, N. Borregaard, and D.L. Bratton. 2004. Phospholipid flip-flop and phospholipid scramblase 1 (PLSCR1) co- 
localize to uropod rafts in formylated Met-Leu-Phe-stimulated neutrophils. J Biol Chem. 279:17625-17633.

Fujii, T., A. Sakata, S. Nishimura, K. Eto, and S. Nagata. 2015. TMEM16F is required for phosphatidylserine exposure and microparticle release in activated mouse platelets. Proc Natl Acad Sci U S A. 112:12800-12805.

Gadella, B.M., and R.A. Harrison. 2000. The capacitating agent bicarbonate induces protein kinase A-dependent changes in phospholipid transbilayer behavior in the sperm plasma membrane. Development. 127:2407-2420.

Gadella, B.M., N.G. Miller, B. Colenbrander, L.M. van Golde, and R.A. Harrison. 1999. Flow cytometric detection of transbilayer movement of fluorescent phospholipid analogues across the boar sperm plasma membrane: elimination of labeling artifacts. Mol Reprod Dev. 53:108-125.

Gong, E.Y., E. Park, H.J. Lee, and K. Lee. 2009. Expression of Atp8b3 in murine testis and its characterization as a testis specific P-type ATPase. Reproduction. 137:345351.

Goren, M.A., T. Morizumi, I. Menon, J.S. Joseph, J.S. Dittman, V. Cherezov, R.C. Stevens, O.P. Ernst, and A.K. Menon. 2014. Constitutive phospholipid scramblase activity of a $\mathrm{G}$ protein-coupled receptor. Nature communications. 5:5115.

Griffin, D.A., R.W. Johnson, J.M. Whitlock, E.R. Pozsgai, K.N. Heller, W.E. Grose, W.D. Arnold, Z. Sahenk, H.C. Hartzell, and L.R. Rodino-Klapac. 2016. Defective membrane fusion and repair in Anoctamin5-deficient muscular dystrophy. Human molecular genetics. 25:1900-1911.

Gyobu, S., H. Miyata, M. Ikawa, D. Yamazaki, H. Takeshima, J. Suzuki, and S. Nagata. 2016. A Role of TMEM16E Carrying a Scrambling Domain in Sperm Motility. Mol Cell Biol. 36:645-659.

Helming, L., and S. Gordon. 2009. Molecular mediators of macrophage fusion. Trends Cell Biol. 19:514-522.

Hiraizumi, M., K. Yamashita, T. Nishizawa, and O. Nureki. 2019. Cryo-EM structures capture the transport cycle of the P4-ATPase flippase. Science.

Hisamoto, N., A. Tsuge, S.I. Pastuhov, T. Shimizu, H. Hanafusa, and K. Matsumoto. 2018. Phosphatidylserine exposure mediated by $\mathrm{ABC}$ transporter activates the integrin signaling pathway promoting axon regeneration. Nature communications. 9:3099.

Hochreiter-Hufford, A.E., C.S. Lee, J.M. Kinchen, J.D. Sokolowski, S. Arandjelovic, J.A. Call, A.L. Klibanov, Z. Yan, J.W. Mandell, and K.S. Ravichandran. 2013. Phosphatidylserine receptor BAI1 and apoptotic cells as new promoters of myoblast fusion. Nature. 497:263-267. 
Jacquemin, E., O. Bernard, M. Hadchouel, D. Cresteil, J.M.L. De Vree, M. Paul, R.P.J.O. Elferink, P.J. Bosma, E.M. Sokal, E. Sturm, M. Burdelski, M. Dumont, and g.L. Scheffer. 2001. The wide spectrum of multidrug resistance 3 deficiency: From neonatal cholestasis to cirrhosis of adulthood. Gastroenterology. 120:1448-1458.

Kang, M.H., R. Singaraja, and M.R. Hayden. 2010. Adenosine-triphosphate-binding cassette transporter-1 trafficking and function. Trends Cardiovasc Med. 20:41-49.

Kim, H., H. Kim, J. Lee, B. Lee, H.R. Kim, J. Jung, M.O. Lee, and U. Oh. 2018. Anoctamin 9/TMEM16J is a cation channel activated by cAMP/PKA signal. Cell calcium. 71:75-85.

Kim, Y., and J. Chen. 2018. Molecular structure of human P-glycoprotein in the ATPbound, outward-facing conformation. Science. 359:915-919.

Lee, S., Y. Uchida, J. Wang, T. Matsudaira, T. Nakagawa, T. Kishimoto, K. Mukai, T. Inaba, T. Kobayashi, R.S. Molday, T. Taguchi, and H. Arai. 2015. Transport through recycling endosomes requires EHD1 recruitment by a phosphatidylserine translocase. EMBO J. 34:669-688.

Leikina, E., K. Melikov, S. Sanyal, S.K. Verma, B. Eun, C. Gebert, K. Pfeifer, V.A. Lizunov, M.M. Kozlov, and L.V. Chernomordik. 2013. Extracellular annexins and dynamin are important for sequential steps in myoblast fusion. $J$ Cell Biol. 200:109-123.

Levano, K., V. Punia, M. Raghunath, P.R. Debata, G.M. Curcio, A. Mogha, S. Purkayastha, D. McCloskey, J. Fata, and P. Banerjee. 2012. Atp8a1 deficiency is associated with phosphatidylserine externalization in hippocampus and delayed hippocampus-dependent learning. Journal of neurochemistry. 120:302-313.

Li, N., Y. Yang, C. Liang, Q. Qiu, C. Pan, M. Li, S. Yang, L. Chen, X. Zhu, and Y. Hu. 2018. Tmem30a Plays Critical Roles in Ensuring the Survival of Hematopoietic Cells and Leukemia Cells in Mice. Am J Pathol. 188:1457-1468.

Li, Z., V. Venegas, Y. Nagaoka, E. Morino, P. Raghavan, A. Audhya, Y. Nakanishi, and Z. Zhou. 2015. Necrotic Cells Actively Attract Phagocytes through the Collaborative Action of Two Distinct PS-Exposure Mechanisms. PLoS genetics. 11:e1005285.

Liou, A.Y., L.L. Molday, J. Wang, J.P. Andersen, and R.S. Molday. 2019. Identification and functional analyses of disease-associated P4-ATPase phospholipid flippase variants in red blood cells. $J$ Biol Chem.

Liu, L., L. Zhang, L. Zhang, F. Yang, X. Zhu, Z. Lu, Y. Yang, H. Lu, L. Feng, Z. Wang, H. Chen, S. Yan, L. Wang, Z. Ju, H. Jin, and X. Zhu. 2017. Hepatic Tmem30a Deficiency Causes Intrahepatic Cholestasis by Impairing Expression and Localization of Bile Salt Transporters. Am J Pathol. 187:2775-2787. 
Lyden, T.W., A.K. Ng, and N.S. Rote. 1993. Modulation of phosphatidylserine epitope expression by BeWo cells during forskolin treatment. Placenta. 14:177-186.

Malvezzi, M., M. Chalat, R. Janjusevic, A. Picollo, H. Terashima, A.K. Menon, and A. Accardi. 2013. Ca2+-dependent phospholipid scrambling by a reconstituted TMEM16 ion channel. Nature communications. 4:2367.

Martin-Hernandez, E., M.E. Rodriguez-Garcia, A. Camacho, A. Matilla-Duenas, M.T. Garcia-Silva, P. Quijada-Fraile, M. Corral-Juan, P. Tejada-Palacios, R.S. de Las Heras, J. Arenas, M.A. Martin, and F. Martinez-Azorin. 2016. New ATP8A2 gene mutations associated with a novel syndrome: encephalopathy, intellectual disability, severe hypotonia, chorea and optic atrophy. Neurogenetics. 17:259-263.

Martin, S., I. Pombo, P. Poncet, B. David, M. Arock, and U. Blank. 2000. Immunologic stimulation of mast cells leads to the reversible exposure of phosphatidylserine in the absence of apoptosis. Int Arch Allergy Immunol. 123:249-258.

Martin, S., S. Smolders, C. Van den Haute, B. Heeman, S. van Veen, D. Crosiers, I. Beletchi, A. Verstraeten, H. Gossye, G. Gelders, P. Pals, N.N. Hamouda, S. Engelborghs, J.J. Martin, J. Eggermont, P.P. De Deyn, P. Cras, V. Baekelandt, P. Vangheluwe, C. Van Broeckhoven, and B. consortium. 2020. Mutated ATP10B increases Parkinson's disease risk by compromising lysosomal glucosylceramide export. Acta Neuropathol.

Matos, P.M., M. Marin, B. Ahn, W. Lam, N.C. Santos, and G.B. Melikyan. 2013. Anionic lipids are required for vesicular stomatitis virus $\mathrm{G}$ protein-mediated single particle fusion with supported lipid bilayers. J Biol Chem. 288:12416-12425.

Melar, M., D.E. Ott, and T.J. Hope. 2007. Physiological levels of virion-associated human immunodeficiency virus type 1 envelope induce coreceptor-dependent calcium flux. $J$ Virol. 81:1773-1785.

Menon, I., T. Huber, S. Sanyal, S. Banerjee, P. Barr • , S. Canis, J.D. Warren, J. Hwa, T.P. Sakmar, and A.K. Menon. 2011. Opsin Is a Phospholipid Flippase. Current Biology. 21:149-153.

Moss, S.E., and R.O. Morgan. 2004. The annexins. Genome Biol. 5:219.

Murate, M., M. Abe, K. Kasahara, K. Iwabuchi, M. Umeda, and T. Kobayashi. 2015. Transbilayer distribution of lipids at nano scale. J Cell Sci. 128:1627-1638.

Nagata, S. 2010. Apoptosis and autoimmune diseases. Ann N Y Acad Sci. 1209:10-16.

Nagata, S. 2018. Apoptosis and Clearance of Apoptotic Cells. Annu Rev Immunol. 36:489-517.

Nagata, S., J. Suzuki, K. Segawa, and T. Fujii. 2016. Exposure of phosphatidylserine on the cell surface. Cell Death Differ. 23:952-961. 
Naito, T., H. Takatsu, R. Miyano, N. Takada, K. Nakayama, and H.W. Shin. 2015. Phospholipid Flippase ATP10A Translocates Phosphatidylcholine and Is Involved in Plasma Membrane Dynamics. J Biol Chem. 290:15004-15017.

Neumann, B., S. Coakley, R. Giordano-Santini, C. Linton, E.S. Lee, A. Nakagawa, D. Xue, and M.A. Hilliard. 2015. EFF-1-mediated regenerative axonal fusion requires components of the apoptotic pathway. Nature. 517:219-222.

Neumann, J., D. Rose-Sperling, and U.A. Hellmich. 2017. Diverse relations between ABC transporters and lipids: An overview. Biochim Biophys Acta Biomembr. 1859:605-618.

Noh, J.Y., K.M. Lim, O.N. Bae, S.M. Chung, S.W. Lee, K.M. Joo, S.D. Lee, and J.H. Chung. 2010. Procoagulant and prothrombotic activation of human erythrocytes by phosphatidic acid. Am J Physiol Heart Circ Physiol. 299:H347-355.

Onat, O.E., S. Gulsuner, K. Bilguvar, A. Nazli Basak, H. Topaloglu, M. Tan, U. Tan, M. Gunel, and T. Ozcelik. 2013. Missense mutation in the ATPase, aminophospholipid transporter protein ATP8A2 is associated with cerebellar atrophy and quadrupedal locomotion. European journal of human genetics : EJHG. 21:281-285.

Ory, S., M. Ceridono, F. Momboisse, S. Houy, S. Chasserot-Golaz, D. Heintz, V. Calco, A.M. Haeberle, F.A. Espinoza, P.J. Sims, Y. Bailly, M.F. Bader, and S. Gasman. 2013. Phospholipid scramblase-1-induced lipid reorganization regulates compensatory endocytosis in neuroendocrine cells. The Journal of neuroscience : the official journal of the Society for Neuroscience. 33:3545-3556.

Park, S.Y., Y. Yun, J.S. Lim, M.J. Kim, S.Y. Kim, J.E. Kim, and I.S. Kim. 2016. Stabilin2 modulates the efficiency of myoblast fusion during myogenic differentiation and muscle regeneration. Nature communications. 7:10871.

Paterson, J.K., K. Renkema, L. Burden, M.S. Halleck, R.A. Schlegel, P. Williamson, and D.L. Daleke. 2006. Lipid Specific Activation of the Murine P4-ATPase Atp8a1 (ATPase II). Biochemistry. 45:5367-5376.

Rival, C.M., W. Xu, L.S. Shankman, S. Morioka, S. Arandjelovic, C.S. Lee, K.M. Wheeler, R.P. Smith, L.B. Haney, B.E. Isakson, S. Purcell, J.J. Lysiak, and K.S. Ravichandran. 2019. Phosphatidylserine on viable sperm and phagocytic machinery in oocytes regulate mammalian fertilization. Nature communications. $10: 4456$.

Roland, B.P., T. Naito, J.T. Best, C. Arnaiz-Yepez, H. Takatsu, R.J. Yu, H.W. Shin, and T.R. Graham. 2019. Yeast and human P4-ATPases transport glycosphingolipids using conserved structural motifs. J Biol Chem. 294:1794-1806. 
Sahu, S.K., S.N. Gummadi, N. Manoj, and G.K. Aradhyam. 2007. Phospholipid scramblases: an overview. Arch Biochem Biophys. 462:103-114.

Sakuragi, T., H. Kosako, and S. Nagata. 2019. Phosphorylation-mediated activation of mouse Xkr8 scramblase for phosphatidylserine exposure. Proc Natl Acad Sci U S A. 116:2907-2912.

Salter, M.W., and B. Stevens. 2017. Microglia emerge as central players in brain disease. Nat Med. 23:1018-1027.

Sapar, M.L., H. Ji, B. Wang, A.R. Poe, K. Dubey, X. Ren, J.Q. Ni, and C. Han. 2018. Phosphatidylserine Externalization Results from and Causes Neurite Degeneration in Drosophila. Cell Rep. 24:2273-2286.

Schroeder, B.C., T. Cheng, Y.N. Jan, and L.Y. Jan. 2008. Expression cloning of TMEM16A as a calcium-activated chloride channel subunit. Cell. 134:1019-1029.

Scudieri, P., E. Caci, A. Venturini, E. Sondo, G. Pianigiani, C. Marchetti, R. Ravazzolo, F. Pagani, and L.J. Galietta. 2015. Ion channel and lipid scramblase activity associated with expression of TMEM16F/ANO6 isoforms. J Physiol. 593:38293848.

Segawa, K., S. Kurata, and S. Nagata. 2016. Human Type IV P-type ATPases That Work as Plasma Membrane Phospholipid Flippases and Their Regulation by Caspase and Calcium. J Biol Chem. 291:762-772.

Segawa, K., S. Kurata, Y. Yanagihashi, T.R. Brummelkamp, F. Matsuda, and S. Nagata. 2014. Caspase-mediated cleavage of phospholipid flippase for apoptotic phosphatidylserine exposure. Science. 344:1164-1168.

Shin, H.W., and H. Takatsu. 2019. Substrates of P4-ATPases: beyond aminophospholipids (phosphatidylserine and phosphatidylethanolamine). FASEB J. 33:3087-3096.

Shlomovitz, I., M. Speir, and M. Gerlic. 2019. Flipping the dogma - phosphatidylserine in non-apoptotic cell death. Cell Commun Signal. 17:139.

Siggs, O.M., C.N. Arnold, C. Huber, E. Pirie, Y. Xia, P. Lin, D. Nemazee, and B. Beutler. 2011a. The P4-type ATPase ATP11C is essential for B lymphopoiesis in adult bone marrow. Nat Immunol. 12:434-440.

Siggs, O.M., B. Schnabl, B. Webb, and B. Beutler. 2011b. X-linked cholestasis in mouse due to mutations of the P4-ATPase ATP11C. Proceedings of the National Academy of Sciences. 108:7890-7895.

Sims, P.J., T. Wiedmer, C.T. Esmon, H.J. Weiss, and S.J. Shattil. 1989. Assembly of the platelet prothrombinase complex is linked to vesiculation of the platelet plasma membrane. Studies in Scott syndrome: an isolated defect in platelet procoagulant activity. J Biol Chem. 264:17049-17057. 
Smit, J.J., A.H. Schinkel, R.P. Oude Elferink, A.K. Groen, E. Wagenaar, L. van Deemter, C.A. Mol, R. Ottenhoff, N.M. van der Lugt, M.A. van Roon, and et al. 1993. Homozygous disruption of the murine mdr2 P-glycoprotein gene leads to a complete absence of phospholipid from bile and to liver disease. Cell. 75:451-462.

Stowell, S.R., S. Karmakar, C.J. Stowell, M. Dias-Baruffi, R.P. McEver, and R.D. Cummings. 2007. Human galectin-1, -2 , and -4 induce surface exposure of phosphatidylserine in activated human neutrophils but not in activated $\mathrm{T}$ cells. Blood. 109:219-227.

Suzuki, J., D.P. Denning, E. Imanishi, H.R. Horvitz, and S. Nagata. 2013a. Xk-related protein 8 and CED-8 promote phosphatidylserine exposure in apoptotic cells. Science. 341:403-406.

Suzuki, J., T. Fujii, T. Imao, K. Ishihara, H. Kuba, and S. Nagata. 2013b. Calciumdependent phospholipid scramblase activity of TMEM16 protein family members. J Biol Chem. 288:13305-13316.

Suzuki, J., E. Imanishi, and S. Nagata. 2014. Exposure of phosphatidylserine by Xkrelated protein family members during apoptosis. J Biol Chem. 289:30257-30267.

Suzuki, J., E. Imanishi, and S. Nagata. 2016. Xkr8 phospholipid scrambling complex in apoptotic phosphatidylserine exposure. Proc Natl Acad Sci US A. 113:9509-9514.

Suzuki, J., M. Umeda, P.J. Sims, and S. Nagata. 2010. Calcium-dependent phospholipid scrambling by TMEM16F. Nature. 468:834-838.

Takada, N., T. Naito, T. Inoue, K. Nakayama, H. Takatsu, and H.W. Shin. 2018. Phospholipid-flipping activity of P4-ATPase drives membrane curvature. EMBO J. 37:e97705.

Takada, N., H. Takatsu, R. Miyano, K. Nakayama, and H.W. Shin. 2015. ATP11C mutation is responsible for the defect in phosphatidylserine uptake in UPS-1 cells. Journal of lipid research. 56:2151-2157.

Takatsu, H., K. Baba, T. Shima, H. Umino, U. Kato, M. Umeda, K. Nakayama, and H.W. Shin. 2011. ATP9B, a P4-ATPase (a Putative Aminophospholipid Translocase), Localizes to the trans-Golgi Network in a CDC50 Protein-independent Manner. $J$. Biol. Chem. 286:38159-38167.

Takatsu, H., M. Takayama, T. Naito, N. Takada, K. Tsumagari, Y. Ishihama, K. Nakayama, and H.W. Shin. 2017. Phospholipid flippase ATP11C is endocytosed and downregulated following $\mathrm{Ca} 2+-$ mediated protein kinase $\mathrm{C}$ activation. Nature communications. 8:1423.

Takatsu, H., G. Tanaka, K. Segawa, J. Suzuki, S. Nagata, K. Nakayama, and H.W. Shin. 2014. Phospholipid Flippase Activities and Substrate Specificities of Human Type 
IV P-type ATPases Localized to the Plasma Membrane. J Biol Chem. 289:3354333556.

Timcenko, M., J.A. Lyons, D. Januliene, J.J. Ulstrup, T. Dieudonne, C. Montigny, M.R. Ash, J.L. Karlsen, T. Boesen, W. Kuhlbrandt, G. Lenoir, A. Moeller, and P. Nissen. 2019. Structure and autoregulation of a P4-ATPase lipid flippase. Nature. 571:366-370.

Tsuchiya, M., Y. Hara, M. Okuda, K. Itoh, R. Nishioka, A. Shiomi, K. Nagao, M. Mori, Y. Mori, J. Ikenouchi, R. Suzuki, M. Tanaka, T. Ohwada, J. Aoki, M. Kanagawa, T. Toda, Y. Nagata, R. Matsuda, Y. Takayama, M. Tominaga, and M. Umeda. 2018. Cell surface flip-flop of phosphatidylserine is critical for PIEZO1-mediated myotube formation. Nature communications. 9:2049.

Tsuji, T., J. Cheng, T. Tatematsu, A. Ebata, H. Kamikawa, A. Fujita, S. Gyobu, K. Segawa, H. Arai, T. Taguchi, S. Nagata, and T. Fujimoto. 2019. Predominant localization of phosphatidylserine at the cytoplasmic leaflet of the ER, and its TMEM16Kdependent redistribution. Proc Natl Acad Sci U S A. 116:13368-13373.

van den Eijnde, S.M., M.J. van den Hoff, C.P. Reutelingsperger, W.L. van Heerde, M.E. Henfling, C. Vermeij-Keers, B. Schutte, M. Borgers, and F.C. Ramaekers. 2001. Transient expression of phosphatidylserine at cell-cell contact areas is required for myotube formation. J Cell Sci. 114:3631-3642.

van der Velden, L.M., C.G.K. Wichers, A.E.D. van Breevoort, J.A. Coleman, R.S. Molday, R. Berger, L.W.J. Klomp, and S.F.J. van de Graaf. 2010. Heteromeric Interactions Required for Abundance and Subcellular Localization of Human CDC50 Proteins and Class 1 P4-ATPases. Journal of Biological Chemistry. 285:40088-40096.

van Meer, G., D.R. Voelker, and G.W. Feigenson. 2008. Membrane lipids: where they are and how they behave. Nat Rev Mol Cell Biol. 9:112-124.

Verma, S.K., E. Leikina, K. Melikov, C. Gebert, V. Kram, M.F. Young, B. Uygur, and L.V. Chernomordik. 2018. Cell-surface phosphatidylserine regulates osteoclast precursor fusion. J Biol Chem. 293:254-270.

Wakatsuki, S., and T. Araki. 2017. Specific phospholipid scramblases are involved in exposure of phosphatidylserine, an "eat-me" signal for phagocytes, on degenerating axons. Communicative \& integrative biology. 10:e1296615.

Wang, J., L.L. Molday, T. Hii, J.A. Coleman, T. Wen, J.P. Andersen, and R.S. Molday. 2018. Proteomic Analysis and Functional Characterization of P4-ATPase Phospholipid Flippases from Murine Tissues. Scientific reports. 8:10795.

Wang, L., C. Beserra, and D.L. Garbers. 2004. A novel aminophospholipid transporter exclusively expressed in spermatozoa is required for membrane lipid asymmetry 
and normal fertilization. Developmental biology. 267:203-215.

Wesseling, M.C., L. Wagner-Britz, D.B. Nguyen, S. Asanidze, J. Mutua, N. Mohamed, B. Hanf, M. Ghashghaeinia, L. Kaestner, and I. Bernhardt. 2016. Novel Insights in the Regulation of Phosphatidylserine Exposure in Human Red Blood Cells. Cellular physiology and biochemistry : international journal of experimental cellular physiology, biochemistry, and pharmacology. 39:1941-1954.

Whitlock, J.M., and H.C. Hartzell. 2017. Anoctamins/TMEM16 Proteins: Chloride Channels Flirting with Lipids and Extracellular Vesicles. Annu Rev Physiol. 79:119-143.

Wielders, S.J., J. Broers, H. ten Cate, P.W. Collins, E.M. Bevers, and T. Lindhout. 2009. Absence of platelet-dependent fibrin formation in a patient with Scott syndrome. Thrombosis and haemostasis. 102:76-82.

Wilen, C.B., J.C. Tilton, and R.W. Doms. 2012. HIV: cell binding and entry. Cold Spring Harb Perspect Med. 2.

Wu, N., V. Cernysiov, D. Davidson, H. Song, J. Tang, S. Luo, Y. Lu, J. Qian, I.E. Gyurova, S.N. Waggoner, V.Q. Trinh, R. Cayrol, A. Sugiura, H.M. McBride, J.F. Daudelin, N. Labrecque, and A. Veillette. 2020. Critical Role of Lipid Scramblase TMEM16F in Phosphatidylserine Exposure and Repair of Plasma Membrane after Pore Formation. Cell Rep. 30:1129-1140 e1125.

Wu, Z., H.M. Ma, T. Kukita, Y. Nakanishi, and H. Nakanishi. 2010. Phosphatidylserinecontaining liposomes inhibit the differentiation of osteoclasts and trabecular bone loss. J Immunol. 184:3191-3201.

Xu, P., J. Okkeri, S. Hanisch, R.-Y. Hu, Q. Xu, T.G. Pomorski, and X.-Y. Ding. 2009. Identification of a novel mouse P4-ATPase family member highly expressed during spermatogenesis. Journal of Cell Science. 122:2866-2876.

Yabas, M., L.A. Coupland, D. Cromer, M. Winterberg, N.C. Teoh, J. D'Rozario, K. Kirk, S. Broer, C.R. Parish, and A. Enders. 2014. Mice Deficient in the Putative Phospholipid Flippase ATP11C Exhibit Altered Erythrocyte Shape, Anemia and Reduced Erythrocyte Lifespan. J Biol Chem. 289:19531-19537.

Yabas, M., C.E. Teh, S. Frankenreiter, D. Lal, C.M. Roots, B. Whittle, D.T. Andrews, Y. Zhang, N.C. Teoh, J. Sprent, L.E. Tze, E.M. Kucharska, J. Kofler, G.C. Farell, S. Broer, C.C. Goodnow, and A. Enders. 2011. ATP11C is critical for the internalization of phosphatidylserine and differentiation of B lymphocytes. Nat Immunol. 12:441-449.

Yagi, M., T. Miyamoto, Y. Sawatani, K. Iwamoto, N. Hosogane, N. Fujita, K. Morita, K. Ninomiya, T. Suzuki, K. Miyamoto, Y. Oike, M. Takeya, Y. Toyama, and T. Suda. 
2005. DC-STAMP is essential for cell-cell fusion in osteoclasts and foreign body giant cells. The Journal of experimental medicine. 202:345-351.

Yang, Y., W. Liu, K. Sun, L. Jiang, and X. Zhu. 2019. Tmem30a deficiency leads to retinal rod bipolar cell degeneration. Journal of neurochemistry. 148:400-412.

Yang, Y., K. Sun, W. Liu, L. Zhang, K. Peng, S. Zhang, S. Li, M. Yang, Z. Jiang, F. Lu, and X. Zhu. 2018. Disruption of Tmem30a results in cerebellar ataxia and degeneration of Purkinje cells. Cell death \& disease. 9:899.

Yang, Y.D., H. Cho, J.Y. Koo, M.H. Tak, Y. Cho, W.S. Shim, S.P. Park, J. Lee, B. Lee, B.M. Kim, R. Raouf, Y.K. Shin, and U. Oh. 2008. TMEM16A confers receptoractivated calcium-dependent chloride conductance. Nature. 455:1210-1215.

Zachowski, A. 1993. Phospholipids in animal eukaryotic membranes: transverse asymmetry and movement. The Biochemical journal. 294 ( Pt 1):1-14.

Zaitseva, E., E. Zaitsev, K. Melikov, A. Arakelyan, M. Marin, R. Villasmil, L.B. Margolis, G.B. Melikyan, and L.V. Chernomordik. 2017. Fusion Stage of HIV-1 Entry Depends on Virus-Induced Cell Surface Exposure of Phosphatidylserine. Cell Host Microbe. 22:99-110 e117.

Zhang, L., Y. Yang, S. Li, S. Zhang, X. Zhu, Z. Tai, M. Yang, Y. Liu, X. Guo, B. Chen, Z. Jiang, F. Lu, and X. Zhu. 2017. Loss of Tmem30a leads to photoreceptor degeneration. Scientific reports. 7:9296.

Zhang, S., W. Liu, Y. Yang, K. Sun, S. Li, H. Xu, M. Yang, L. Zhang, and X. Zhu. 2019. TMEM30A deficiency in endothelial cells impairs cell proliferation and angiogenesis. J Cell Sci. 132.

Zhu, X., R.T. Libby, W.N. de Vries, R.S. Smith, D.L. Wright, R.T. Bronson, K.L. Seburn, and S.W. John. 2012. Mutations in a P-type ATPase gene cause axonal degeneration. PLoS genetics. 8:e1002853. 
每都大学C50A

$\bigcap$ PS ove है? ant 0 s $15 ?$
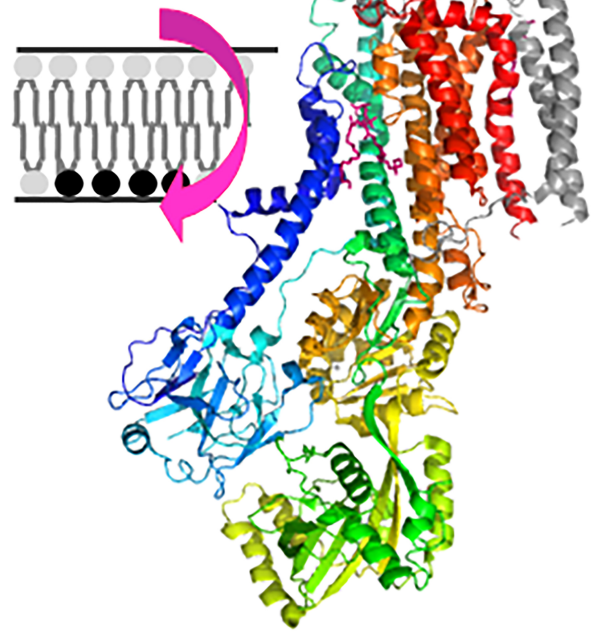

Flippase (P4-ATPase)

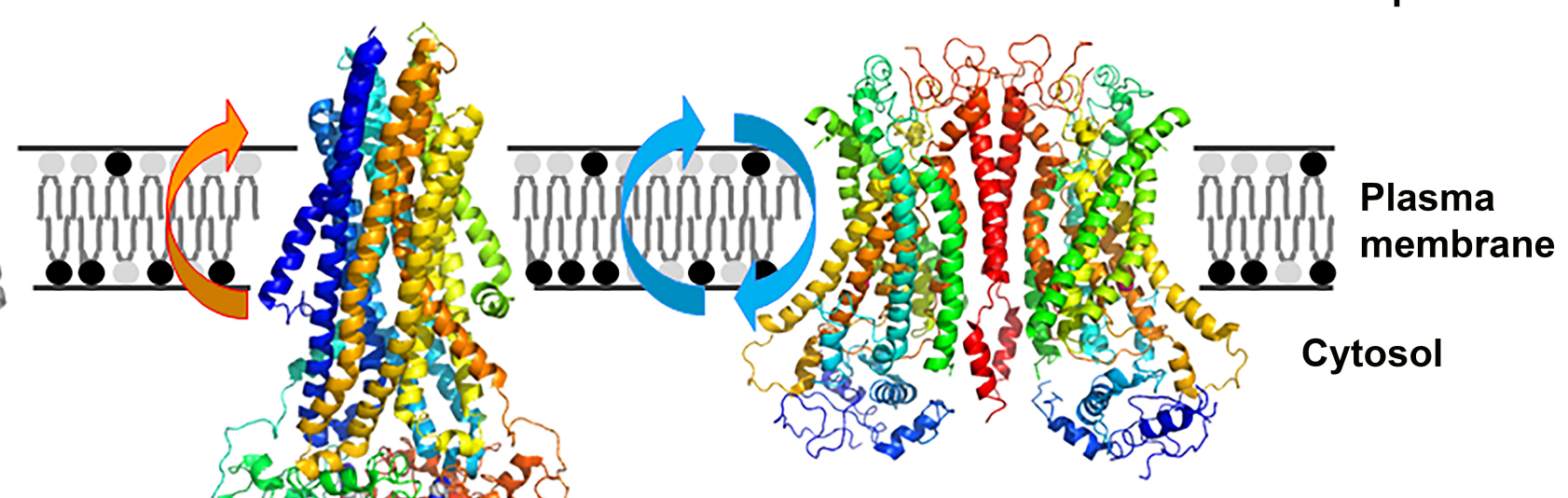

Scramblase (TMEM16)
Floppase (ABC transporter)

Figure 1 Shin and Takatsu 
京都大学 KYOTO UNIVERSITY ATP11A ATP11C

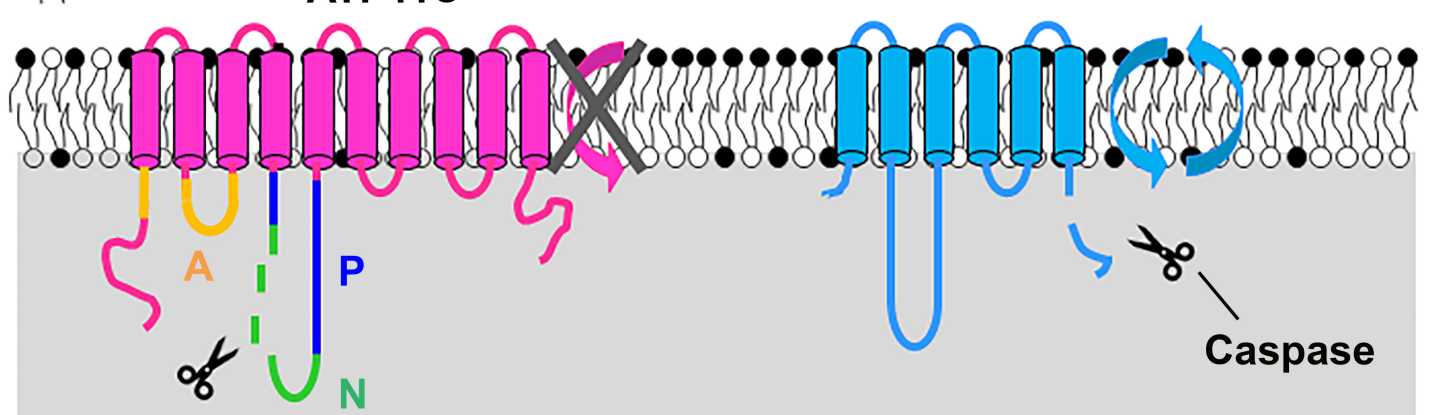

Inactivation of flippases

Activation of scrambling

Figure 2 Shin and Takatsu 


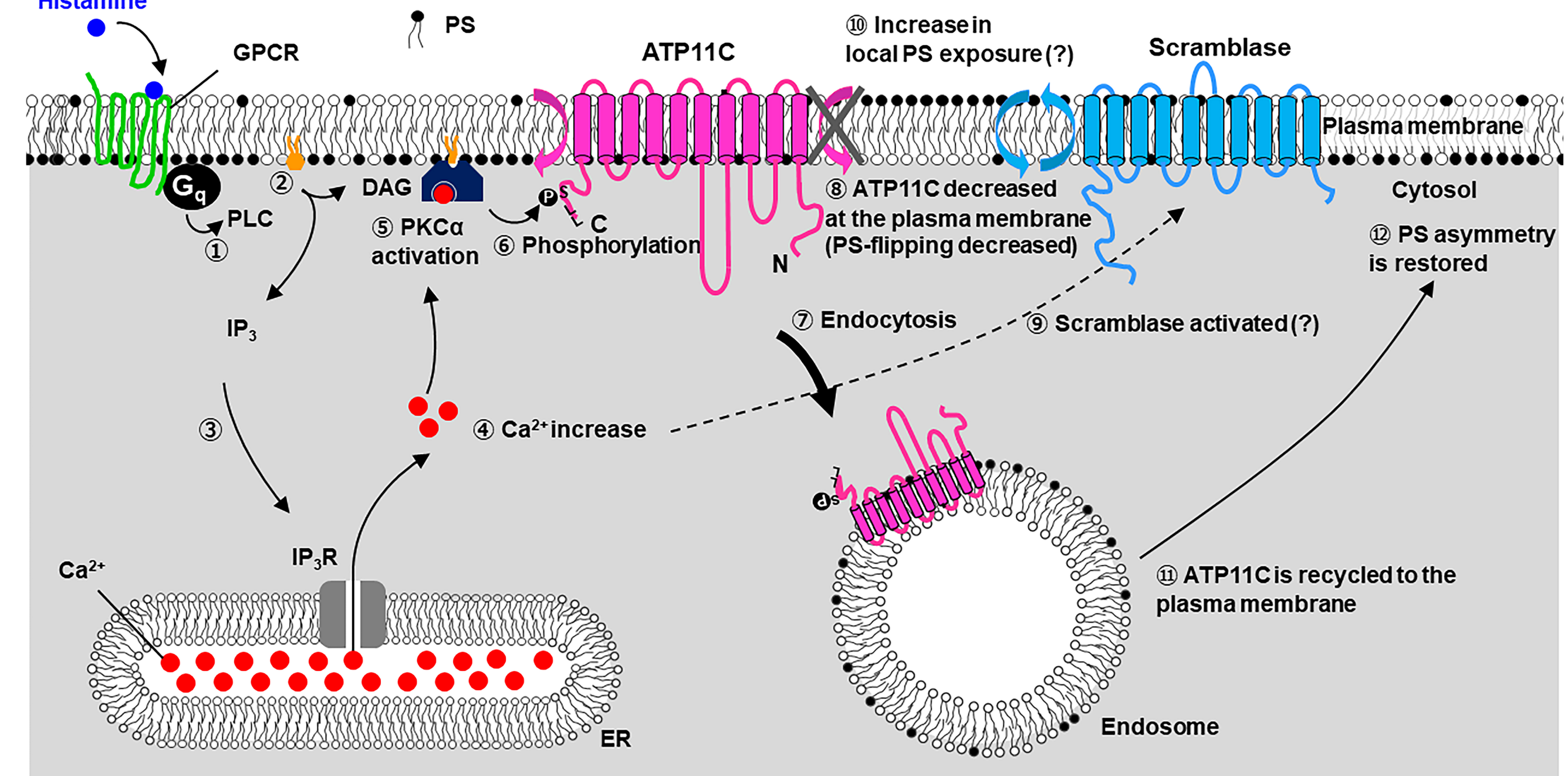

Figure 3 Shin \& Takatsu 
Table 1 P4-ATPase family

\begin{tabular}{|c|c|c|c|c|}
\hline P4-ATPase & $\begin{array}{l}\text { CDC50 } \\
\text { partner }^{\mathrm{a}}\end{array}$ & Substrate $^{\mathrm{b}}$ & $\begin{array}{l}\text { Cellular } \\
\text { localization }^{\mathrm{c}}\end{array}$ & $\begin{array}{l}\text { Tissue } \\
\text { distribution }^{\mathrm{d}}\end{array}$ \\
\hline ATP8A1 & CDC50A & $\mathrm{PS}>\mathrm{PE}$ & LE, RE, Golgi, PM & Most tissues \\
\hline АТР8А2 & CDC50A & $\mathrm{PS}>\mathrm{PE}$ & Golgi, RE, PM & $\begin{array}{l}\text { Retina, brain, } \\
\text { testis }\end{array}$ \\
\hline ATP8B1 & $\mathrm{CDC} 50 \mathrm{~A}>\mathrm{B}$ & PC (PS?) & PM & Ubiquitous \\
\hline ATP8B2 & CDC50A, B & $\mathrm{PC}$ & PM & \\
\hline ATP8B3 & & PS? & & Testis \\
\hline ATP8B4 & CDC50A, B & & $\mathrm{PM}$ & \\
\hline $\begin{array}{l}\text { ATP8B5 } \\
\text { (mouse only) }\end{array}$ & & & PM? & Testis \\
\hline АТР9A & - & & EE, RE, Golgi & \\
\hline АТР9В & - & & Golgi & \\
\hline ATP10A & CDC50A & $\mathrm{PC}$ & PM & \\
\hline ATP10B & CDC50A & PC, GlcCer & LE & \\
\hline ATP10D & CDC50A & GlcCer & $\mathrm{PM}$ & \\
\hline ATP11A & CDC50A & PS, PE & $\mathrm{PM}$ & Ubiquitous \\
\hline ATP11B & CDC50A & $\mathrm{PS}>\mathrm{PE}$ & $\mathrm{EE}, \mathrm{RE}$ & \\
\hline ATP11C & CDC50A & $\mathrm{PS}>\mathrm{PE}$ & PM & Ubiquitous \\
\hline
\end{tabular}

PS, phosphatidylserine; PE, phosphatidylethanolamine; PC, phosphatidylcholine; GlcCer, glucosylceramide; PM, plasma membrane; LE, late endosome; RE, recycling endosome; EE, early endosome; -, not required

a Bryde et al., 2010; van der Velden et al., 2010; Takatsu et al., 2011; Naito et al., 2015; Andersen et al., 2016; Shin and Takatsu, 2019

${ }^{\mathrm{b}}$ Coleman et al., 2011; Takatsu et al., 2014; Lee et al., 2015; Andersen et al., 2016; Wang et al., 2018; Roland et al., 2019; Shin and Takatsu, 2019; Martin et al., 2020 c Bryde et al., 2010; van der Velden et al., 2010; Coleman et al., 2011; Takatsu et al., 2011; Lee et al., 2015; Andersen et al., 2016; Shin and Takatsu, 2019 
d Bull et al., 1998; Coleman et al., 2009; Gong et al., 2009; Xu et al., 2009; Cacciagli et al., 2010; Segawa et al., 2016; Andersen et al., 2016 
Table 2 Lipid translocases in the ABC transporter family

\begin{tabular}{ll}
\hline ABC transporter & Deduced substrate $^{\mathrm{a}}$ \\
\hline ABCA1 & PC, PS, Chol \\
ABCA2 & Chol, PE, PS \\
ABCA3 & PC, PG, PE, Chol \\
\hline ABCA4 & N-retinylidene-PE, PE \\
\hline ABCA5 & Chol \\
\hline ABCA7 & PC, SM, Chol? \\
\hline ABCA12 & Cer, GlcCer \\
\hline ABCB1 & PC, PS, PE, SM, Chol, GlcCer, PAF \\
\hline ABCB4 & PC, PE, SM \\
\hline ABCB11 & Bile salt \\
\hline ABCC1 & PC, PS, SM, GlcCer, Bile salt \\
\hline ABCG1 & Chol, PS, PC, SM \\
\hline ABCG2 & PC, PS \\
\hline ABCG4 & Chol \\
\hline ABCG5/G8 & Chol, sitosterol \\
\hline
\end{tabular}

PC, phosphatidylcholine; PS, phosphatidylserine; Chol, cholesterol; PE, phosphatidylethanolamine; PG, phosphatidylglycerol; SM, sphingomyelin; Cer, ceramide; GlcCer, glucosylceramide; PAF, platelet activating factor a van Meer et al., 2008; Kang et al., 2010, Coleman et al., 2013; Neumann et al., 2017 
Table 3 TMEM16 and Xkr family

\begin{tabular}{|c|c|c|c|}
\hline $\begin{array}{l}\text { TMEM16 } \\
\text { family }\end{array}$ & Primary function $^{\text {a }}$ & $\begin{array}{l}\text { Cellular } \\
\text { localization }^{\mathrm{a}}\end{array}$ & Tissue distribution $^{\mathrm{a}}$ \\
\hline TMEM16A & $\mathrm{Cl}^{-}$channel & PM & Most tissues \\
\hline TMEM16B & $\mathrm{Cl}^{-}$channel & PM & Eye \\
\hline TMEM16C & Lipid scramblase & PM & Brain \\
\hline TMEM16D & Lipid scramblase & PM & Brain, eye, ovary, uterus \\
\hline TMEM16E & Lipid scramblase & Intracellular & Muscle, bone, testis \\
\hline TMEM16F & Lipid scramblase & PM & Ubiquitous \\
\hline TMEM16G & Lipid scramblase & PM & Intestine \\
\hline TMEM16H & & Intracellular & Ubiquitous \\
\hline TMEM16J & Lipid scramblase & $\mathrm{PM}$ & Intestine, stomach, skin \\
\hline TMEM16K & Lipid scramblase & Intracellular & Ubiquitous \\
\hline Xkr family & Primary function $^{\mathrm{b}}$ & $\begin{array}{l}\text { Cellular } \\
\text { localization }^{\mathrm{b}}\end{array}$ & Tissue distribution $^{\mathrm{b}}$ \\
\hline $\mathrm{Xkr1}$ & & $\mathrm{PM}$ & Most tissues \\
\hline $\mathrm{Xkr} 2$ & & Intracellular, PM & Placenta, adrenal gland \\
\hline $\mathrm{Xkr3}$ & & & Testis \\
\hline $\mathrm{Xkr} 4$ & Lipid scrambling & $\mathrm{PM}$ & Brain, eye, skin \\
\hline $\mathrm{Xkr} 5$ & & $\mathrm{PM}$ & \\
\hline Xkr6 & & $\mathrm{PM}$ & \\
\hline $\mathrm{Xkr} 7$ & & $\mathrm{PM}$ & \\
\hline $\mathrm{Xkr8}$ & Lipid scrambling & $\mathrm{PM}$ & Ubiquitous \\
\hline Xkr9 & Lipid scrambling & PM & Intestine, stomach \\
\hline
\end{tabular}

PM, plasma membrane; Intracellular, intracellular membranes 
a Yang et al., 2008; Schroeder et al., 2008; Caputo et al., 2008; Suzuki et al., 2013b;

Nagata et al., 2016; Whitlock and Hartzell, 2016; Falzone et al., 2018

${ }^{\mathrm{b}}$ Calenda et al., 2006; Suzuki et al., 2014; Nagata et al., 2016 